\title{
Invasive Infections for Endemic Fungi in Pediatrics in Guatemala
}

\author{
Julio Werner Juárez Lorenzanaํㅜ, María Luisa Navarro Gómez², Andrea Palma ${ }^{3}$ \\ ${ }^{1}$ Comprehensive Care Unit of HIV and Chronic Infections “Dr. Carlos Rodolfo Mejia”, Roosevelt Hospital, \\ Guatemala City, Guatemala \\ ${ }^{2}$ Infectious Diseases Section, Pediatrics Service, School of Medicine, Complutense University of Madrid, \\ University General Universitario Gregorio Marañón, Madrid, Spain \\ ${ }^{3}$ General Physician Rafael Landívar University, Guatemala City, Guatemala \\ Email: jwerner_juarez@hotmail.com
}

How to cite this paper: Lorenzana, J.W.J., Gómez, M.L.N. and Palma, A. (2018) Invasive Infections for Endemic Fungi in Pediatrics in Guatemala. World Journal of AIDS, 8, 63-75.

https://doi.org/10.4236/wja.2018.83006

Received: June 12, 2018

Accepted: August 20, 2018

Published: August 23, 2018

Copyright $\odot 2018$ by authors and Scientific Research Publishing Inc. This work is licensed under the Creative Commons Attribution International License (CC BY 4.0).

http://creativecommons.org/licenses/by/4.0/

\begin{abstract}
Background: Invasive fungal infections are common opportunistic diseases in patients with AIDS, other conditions related to immunodeficiency and healthy infants. Most publications on this subject are related to industrialized countries, and in adult population, with limited data in Latin America (except for Brazil, Colombia, and Argentina), and especially in pediatric population. These patients present a variety of clinical manifestations representing a diagnostic and therapeutic challenge for the health system. Objective: The objective of the study is to describe the epidemiological and laboratory characteristics of children with invasive fungal infections in Guatemala. Methods: A review of the microbiology service database was carried out at Roosevelt Hospital in Guatemala. Positive cultures were taken from children under 15 years of age, in a period of seven years, from 2007 to 2014, with its corresponding medical history. Results: Finally, 23 isolates were documented but only 15 patients were included in the study with complete information; 10 Histoplasma capsulatum cases, 4 Cryptococcus neoformans cases and 1 Coccidioidess $p$ case. The average age was 7 years old for Histoplasma and 9 years old for Criptococo, with an age range from 6 months to 14 years. Around $60 \%$ of the patients were older than 5 years, of which, more than two-thirds were HIV positive children without antiretroviral therapy, who presented an invasive fungal infection at the time of HIV diagnosis. These infections are endemic in Guatemala, so the distribution was mostly uniform. Around $80 \%$ of the patients had some disease related to immunodeficiency and $70 \%$ were infected with human immunodeficiency virus (HIV). The microbiological isolation was from blood, bone marrow, lymph nodes, cerebrospinal fluid and urine. The predominant laboratory findings were decrease in hematological
\end{abstract}


series. The most frequent clinical syndromes were fever, adenomegaly, hepatosplenomegaly, respiratory, gastrointestinal, neurological and weight loss. Mortality rate was $53 \%$ (from them, $62 \%$ were HIV positive). From these patients, an $87 \%$ did not receive antifungal treatment in time due to late diagnosis of the infection. Conclusions: These infections should be considered when treating pediatric patients from tropical regions, with nonspecific systemic symptoms and signs, lymph node involvement and hematological alterations related to the mononuclear phagocytic system, mainly if they are patients infected by HIV in an advanced stage, infants, or children with a disease that weakens the immune system. When there is a high suspicion of a fungal infection, screening for HIV is mandatory; cultures should be taken early and together with rapid diagnostic tests. An antifungal treatment should be started immediately and then modified accordingly to laboratory results.

\section{Keywords}

Cryptococcosis, Histoplasmosis, Coccidioidomycosis, Invasive Infection, Pediatrics, Immunodeficiency, HIV (Human Immunodeficiency Virus)

\section{Introduction}

Along the pediatric population, there are some groups with an increased risk for invasive fungal infection (IFI). Within these risk groups, are found extremely premature newborns (especially less than $1000 \mathrm{~g}$ ), children who require prolonged admission in intensive care units, patients with hemato-oncological diseases and patients who undergo precursor hematopoietic or solid organ transplants. Also children who have primary or acquired immunodeficiency, such as HIV infection or prolonged immunosuppressive treatment are at risk for IFI [1] [2].

Histoplasma capsulatum is a fungus acquired by inhaling thermally dimorphic microconidia (environmental mold becomes yeast at $37^{\circ} \mathrm{C}$ ), produced by the micellar form. There are two biotypes able to infect humans: $H$. capsulatumvarcapsulatum and $H$. capsulatumvarduboissii.

In Latin America, the prevalence ranges from $2.1 \%$ to $20 \%$ and is defined as AIDS related event in 30\% - 75\% cases. Lung disease is the most common presentation followed by cutaneous diseases. Dissemination occurs in more than $50 \%$ of patients, and in these cases, up to $20 \%$ are co-infected with tuberculosis. More than $7 \%$ of all HIV patients in Guatemala manifest this infection in a disseminated way [3] [4].

For the immunological diagnosis, the $\mathrm{CD} 4$ count is usually $<150 \mathrm{cel} / \mathrm{ul}$, although there is no threshold established in infants. It affects people immunosuppressed mainly by HIV, healthy infants from endemic regions $<2$ years, patients with rheumatological diseases under immunosuppressive therapy, children with acute lymphoblastic leukemia without neutropenia and patients after 
undergone a solid organ transplantation [5] [6].

When IFI is in its disseminated form, the manifestations are nonspecific and systemic.

It is considered the most common endemic mycosis in the United States and Central America, causing localized epidemics related to environmental alterations such as exposure to bird droppings, bats and dust [7].

Cryptococcosis is produced by Cryptococcus neoformans varneoformans, which is responsible for $95 \%$ of cases, and Cryptococcus neoformansvargattii, mostly observed inimmunocompetent patients. This infection is the second cause of death by fungi in Latin America. This yeast is encapsulated and is acquired by inhalation and affects patients with AIDS, transplant recipients, Sarcoidosis patients, chronic lymphoproliferative and auto immunedisease patients. It has also been described in children without immunodeficiency and patients without underlying disease up to $5 \%-10 \%$ [4] [8] [9].

The most common manifestation in Latin America is meningoencephalitis, and $85 \%$ of cases are produced by $C$. neoformans, of which, $80 \%$ are associated with HIV infection. Lung disease without dissemination is rare in children. This fungal infection can also affect lung, bone and skin tissues.

Coccidioides species include Coccidioides immitis in California, and Coccidioides posadasii in Arizona, Texas, Mexico, Central America and South America. In Central America, there are two endemic areas: the Motagua River Valley, Guatemala, and the Comaya Valley, Honduras. This dimorphic fungi, is acquired by inhaling the arthroconidia, which are spores that grow in warm soil in arid areas of the Americas. It is estimated that $60 \%$ of infected people do not develop symptoms or the symptoms are mild.

This infection is self-limited in more than $90 \%$ of children. Of those who do not limit the disease, $40 \%$ have flu-like symptoms, others could go up to disseminated infection (less than 5\%), being immunosuppression a risk factor, even though it can affect healthy children. At lung level, it causes nodules and cavities (uncommon in children). Children with primary lung infection mainly may have fever, malaise, and chest pain, but it could affect bone and skin tissue, meninges and lymph nodes. In endemic areas, cough, fever, and cervical adenopathies are a useful triad for diagnosis [10] [11].

The incidence of these fungi infections has decreased due to antiretroviral treatment, but they continue affecting HIV infected patients in regions where the diagnosis of viral and fungal diseases is insufficient. The three fungi are endemic in Guatemala. We elaborated this review because of the poor information available on these infections in children.

\section{Methodology}

This retrospective descriptive study was carried out in the pediatric department of the Roosevelt Hospital, a reference center in Guatemala.

The database of positive cultures from pediatric patients for endemic fungi of 
the microbiology department was reviewed. Data used was from 2007 to 2014, excluding diagnoses made by rapid tests. Enrollment was limited to pediatric patients (aged under 18 years) with newly diagnosed invasive fungi infection with medical records available.

The files were reviewed, focusing on epidemiological variables (gender, age and origin), clinical (predominant clinical manifestations and associated medical conditions), fungi (site of fungus growth) and laboratory data.

Qualitative variables were summarized using counts and proportions. Since data collected were considered as population-based, no hypothesis testing was conducted.

\section{Results}

\section{1) Microbiological isolation:}

For seven years, 23 isolates were documented:

a) Cryptococcus neoformans (12 cases)

b) Histoplasma capsulatum (10 cases)

c) Coccidioides sp. (1 case)

The study included ten patients with histoplasmosis, 4 with Cryptococcosis and 1Coccidioidomycosis case.

From the 12 Cryptococcus cultures, 8 of them, blood (1), cerebrospinal fluid (CSF) (3), urine (2), tracheal aspirate (1) and skin (1), were not included in the analysis because clinical data was not available.

\section{2) Demographic data and associated medical conditions:}

Table 1 shows patients characteristics, including the type of infection, age, and gender.

In the case of histoplasmosis, the average age was seven years old, and this infection occurred more in males (6/10).

Overall, $70 \%$ of the children were infected by HIV and one of them was coinfected by Hepatitis C virus (HCV). Other conditions were juvenile dermatomyositis under immunosuppressive therapy and two healthy infants with acute progressive disseminated histoplasmosis.

In the case of cryptococcosis, the average age was nine years old, and the distribution was equal in both genders. Two out of four patients with cryptococcosis had HIV infection. One of the patients had myelomeningocele and chronic renal failure and there was an infant with a urine isolation with no apparently underlying disease.

Regarding to coccidioidomycosis, there was a case in a 13-year-old girl with Down Syndrome.

Belonging the origin, according to regions of the country, more than half of the cases corresponded to central zone and south coast. Histoplasmosis cases had the widest distribution, although $90 \%$ of the cases were in the eastern, central and southern areas of the country.

Overall, distribution of infections was uniform throughout the country, especially in areas with tropical climate. There were no cases in the northern region. 
Table1. Characteristics of children with fungal infections.

\begin{tabular}{cccc}
\hline & Histoplasmosis & Cryptococcosis & Coccidioidomycosis \\
\hline No. of patients & 10 & 4 & 1 \\
Average age years, (SD) & $7(5.67)$ & $9(4.86)$ & $13(0)$ \\
Gender (M/F) & $6 / 4$ & $2 / 2$ & $1 / 0$ \\
HIV+ & $7(70 \%)$ & $2(50 \%)$ & 0 \\
Other diseases & Juvenile & Myelomeningocele & Down's Syndrome \\
Without disease & 2 cases & 1 case & \\
\hline
\end{tabular}

$\mathrm{SD}=$ standard deviation, $\mathrm{M}=$ male, $\mathrm{F}=$ female, $\mathrm{HIV}=$ Human immunodeficiency virus $\mathrm{CRF}=$ chronic renal failure.

Table 2 shows CD4 T lymphocyte count and basal viral load for HIV positive patients according to the type of fungus. From them, $89 \%$ were in stage 3 according to the CDC classification based on CD4 T lymphocite count. Only a one-year old infant was found in stage 2 [12].

Regarding to viral load, patients older than ten years had values below100,000 $\mathrm{cp} / \mathrm{ml}$ while younger children had higher viral load values. These patients were not on antiretroviral therapy because they were diagnosed with HIV along with the fungal infection.

\section{3) Symptoms and signs}

According to Table 3, the most frequent symptom was fever. It occurred in half of the cases of histoplasmosis and cryptococcosis. Other frequent symptoms of histoplasmosis were cough and asthenia. Dyspnea, headache, vomiting, diarrhea, and odynophagia, were less frequently observed, without predominance of a particular infection.

Regarding the clinical signs, we observed that adenomegaly, pallor, hepatosplenomegaly, exanthema, and wasting were the most frequent in histoplasmosis. Craneal hypertension occurred in cryptococcosis and the case of coccidioidomycosis presented suppurative adenomegalias without any other location.

\section{4) Microbiological isolation site and affected systems:}

Table 4 summarizes the isolation according to the type of sample and patient. Most of the isolated fungi were obtained from blood and bone marrow culture, collectively 7 (47\%), ganglion biopsy culture $4(27 \%)$, and CSF culture $2(13 \%)$.

Histoplasma capsulatum was found primarily in blood culture and myeloculture in 7 patients, and ganglion biopsy culture in 3 patients. In one patient, urine and pleural fluid were isolated.

Cryptococcus neoformans was isolated in the cerebrospinal fluid of 2 patients infected with HIV, and in peritoneal fluid and urine. The only case of Coccidioides sp. was found in a culture of a cervical lymph node biopsy sample.

The infection by Histoplasma capsulatum did not affect a specific organ since in all (100\%) of the cases was disseminated (all patients were immunosuppressed and healthy infants); Central Nervous System (CNS) was affected in 50\% of 
Table 2. HIV Infection data according to infection.

\begin{tabular}{ccccc}
\hline & $\begin{array}{c}\text { Age } \\
\text { (years, months }\end{array}$ & $\begin{array}{c}\text { CD4 } \\
(\mathrm{Cel} / \mathrm{ul})\end{array}$ & $\begin{array}{c}\text { Stage according } \\
\text { to CD4 }\end{array}$ & $\begin{array}{c}\text { Viral load } \\
\text { (Cp/ml) }\end{array}$ \\
\hline $\begin{array}{c}\text { Histoplasma } \\
\text { capsulatum }\end{array}$ & 6 & 5 & 3 & 5160 \\
& 2.7 & 17 & 3 & 123,000 \\
& 0.11 & 35 & 3 & 153,000 \\
& 14.11 & 641 & 2 & $10,000,000$ \\
& 3.11 & 325 & 3 & $3,280,134$ \\
Cryptococcus neoformans & 8 & 17 & 3 & 474,043 \\
& 12.4 & 67 & 3 & 8965 \\
& 11.6 & 3 & 3 & 49,667 \\
\hline
\end{tabular}

Table 3. Clinical manifestations.

\begin{tabular}{|c|c|c|c|}
\hline & Histoplasmosis & Cryptococcosis & Coccidioidomycosis \\
\hline \multicolumn{4}{|l|}{ Clinical manifestations } \\
\hline \multicolumn{4}{|l|}{ Symptom } \\
\hline Fever & $5 / 10(50 \%)$ & $2 / 4(50 \%)$ & 0 \\
\hline Cough & $2 / 10(20 \%)$ & $1 / 4(25 \%)$ & 0 \\
\hline Dyspnea & $1 / 10(10 \%)$ & $1 / 4(25 \%)$ & 0 \\
\hline Headache & $1 / 10(10 \%)$ & $1 / 4(25 \%)$ & 0 \\
\hline Vomiting & $1 / 10(10 \%)$ & $1 / 4(25 \%)$ & 0 \\
\hline Diarrhea & $1 / 10(10 \%)$ & $1 / 4(25 \%)$ & 0 \\
\hline Sore throat & $1 / 10(10 \%)$ & 0 & 0 \\
\hline General discomfort & $1 / 10(10 \%)$ & 0 & 0 \\
\hline Asthenia & $2 / 10(20 \%)$ & 0 & 0 \\
\hline \multicolumn{4}{|l|}{$\underline{\text { Signs }}$} \\
\hline Adenomegalia & $4 / 10(40 \%)$ & 0 & $1 / 1(100 \%)$ \\
\hline Wasting & $2 / 10(20 \%)$ & & \\
\hline Pallor & $4 / 10(40 \%)$ & 0 & 0 \\
\hline Rash or purple & $2 / 10(20 \%)$ & 0 & 0 \\
\hline Decreased weight & $1 / 10 / 10 \%)$ & 0 & 0 \\
\hline Seizures & $1 / 10(10 \%)$ & & \\
\hline Hepatosplenomegaly & $3 / 10(30 \%)$ & 0 & 0 \\
\hline Intracranial hypertension & 0 & $1 / 4(25 \%)$ & 0 \\
\hline Sepsis & $1 / 10(10 \%)$ & & \\
\hline
\end{tabular}

Cryptococcus neoformans cases (HIV patients), and Coccidioides sp. affected lymph nodes in the patient infected.

\section{5) Antifungal treatment and deaths:}

According to Table 5, eight of the patients died, mostly histoplasmosis infected patients. More than half of HIV positive infection children with histoplasmosis infection died. The causes of death were related to complications such as pneumonia, septic shock, and marrow aplasia in an average of 18 days after diagnosis. 
Table 4. Isolation Site and affected system.

\begin{tabular}{cccc}
\hline & Histoplasmosis & Cryptococcosis & Coccidioidomycosis \\
\hline Culture results & & & \\
Ganglion culture & $3 / 10(30 \%)$ & 0 & $1 / 1(100 \%)$ \\
CSF & 0 & $2 / 4(50 \%)$ & 0 \\
Blood & $3 / 10(30 \%)$ & 0 & 0 \\
Urine & 0 & $1 / 4(25 \%)$ & 0 \\
Bone marrow & $1 / 10(10 \%)$ & 0 & 0 \\
Peritoneal fluid & 0 & $1 / 4(25 \%)$ & 0 \\
Blood and bone marrow & $2 / 10(20 \%)$ & & \\
Blood, pleural fluid and urine & $1 / 10(10 \%)$ & & \\
Affected system & & & 0 \\
Disseminated & $10 / 10(100 \%)$ & 0 & 0 \\
Lymph nodes & 0 & 0 & 0 \\
CNS & 0 & $2 / 4(50 \%)$ & 0 \\
Urinary system & 0 & $1 / 4(25 \%)$ & \\
Peritoneum & 0 & $1 / 4(25 \%)$ & \\
\hline
\end{tabular}

CSF: cerebrospinal fluid. CNS: Central Nervous System.

Table 5. Antifungal treatment and information on the death of children with fungal infections.

\begin{tabular}{|c|c|c|c|c|c|c|c|}
\hline $\begin{array}{l}\text { Age (years, } \\
\text { months) }\end{array}$ & Sex & Fungal infection & $\mathrm{HIV}+$ & Antifungal treatment & Death & $\begin{array}{c}\text { Death after diagnosis } \\
\text { (days) }\end{array}$ & Cause of death \\
\hline 13 & $\mathrm{M}$ & H. capsulatum & Yes & $\begin{array}{l}\text { Amphotericin Band } \\
\text { Itraconazole }\end{array}$ & Do not & - & - \\
\hline 6 & $\mathrm{M}$ & H. capsulatum & Yes & $\begin{array}{l}\text { Amphotericin Band } \\
\text { Itraconazole }\end{array}$ & Do not & - & - \\
\hline 13 & $\mathrm{~F}$ & C. immitis & Donot & Fluconazole & Do not & - & - \\
\hline 12,4 & $\mathrm{~F}$ & C. neoformans & Yes & $\begin{array}{l}\text { Amphotericin Band } \\
\text { Fluconazole }\end{array}$ & Do not & - & - \\
\hline 1,10 & $\mathrm{M}$ & C. neoformans & Do not & Any & Yes & 14 & Complicated pneumonia \\
\hline 2,7 & $\mathrm{M}$ & H. capsulatum & Yes & Any & Yes & 4 & Severe anemia \\
\hline 11,6 & $\mathrm{M}$ & C. neoformans & Yes & Any & Yes & 8 & Meningitis, pneumonia \\
\hline 0.11 & $\mathrm{~F}$ & H. capsulatum & Yes & Any & Yes & 16 & $\begin{array}{l}\text { Pneumonia, } \\
\text { chronic diarrhea }\end{array}$ \\
\hline 14,11 & $\mathrm{~F}$ & H. capsulatum & Yes & Any & Yes & 10 & $\begin{array}{l}\text { Septic shock, bone } \\
\text { marrow aplasia }\end{array}$ \\
\hline 3,11 & $\mathrm{M}$ & H. capsulatum & Yes & Any & Yes & 80 & $\begin{array}{l}\text { Pneumonia, } \\
\text { septic shock }\end{array}$ \\
\hline 10,6 & $\mathrm{~F}$ & C. neoformans & Do not & Any & Do not & - & - \\
\hline 14 & $\mathrm{~F}$ & H. capsulatum & Do not & Any & Yes & 11 & Septic shock \\
\hline 8 & $\mathrm{M}$ & H. capsulatum & Yes & $\begin{array}{l}\text { Amphotericin B } \\
\text { and Itraconazole }\end{array}$ & Do not & - & - \\
\hline 1,2 & $\mathrm{M}$ & H. capsulatum & Do not & $\begin{array}{l}\text { Amphotericin B } \\
\text { and Itraconazole }\end{array}$ & Do not & - & - \\
\hline 0.6 & $\mathrm{~F}$ & H. capsulatum & Do not & Amphotericin B & Yes & 4 & Multi-organic failure \\
\hline
\end{tabular}


From al the patients, $53 \%$ did not receive any antifungal treatment due to the late diagnosis of the infection. This occurred in $50 \%$ of the patients with histoplasmosis infection and two-thirds of cryptococcosis infected patients.

Histoplasma capsulatum infection was treated with Amphotericine B with or without Itraconazole, for Cryptococcus neoformans infection, Amphotericine B and Fluconazole and for Coccidioides sp. was used Fluconazole.

One of the seven patients who received antifungal treatment died, and from the eight patients that did not received treatment, seven patients died.

\section{Laboratory Results}

\section{1) Hematology:}

Table 6 shows data obtained from laboratory analyses, according to age, sex, and infection. According to hematology data, patients were stratified by sex and age [13].

More than a half (53\%) of patients had leukopenia, 20\% neutropenia and $73 \%$ of the patients had lymphopenia. More than $70 \%$ of children had anemia, and $33 \%$ had thrombocytopenia.

In general, more than $90 \%$ of the patients presented some hematological alteration, a decrease in some of the myeloid or lymphoid series. Lymphopenia and anemia were the predominant symptoms. Overall, children with HIV had lymphopenia (89\%). According to the type of fungus, $70 \%$ of the cases of histoplasmosis and $75 \%$ of cryptococcosis had some hematological alteration.

Table 6. Hematology and blood chemistry results of children with fungal infections

\begin{tabular}{|c|c|c|c|c|c|c|c|c|c|c|c|c|c|}
\hline $\begin{array}{c}\text { Age } \\
\text { (years, months) }\end{array}$ & Sex & $\begin{array}{c}\text { Fungal } \\
\text { infection }\end{array}$ & $\begin{array}{l}\text { WBC } \\
(\mathrm{K} / \mathrm{ul})\end{array}$ & $\begin{array}{l}\text { Neut. } \\
\left(\mathrm{mm}^{3}\right)\end{array}$ & $\begin{array}{l}\text { Lymph. } \\
\left(\mathrm{mm}^{3}\right)\end{array}$ & $\begin{array}{l}\mathrm{Hb} \\
(\mathrm{g} / \mathrm{dl})\end{array}$ & $\begin{array}{l}\mathrm{HT} \\
(\%)\end{array}$ & $\begin{array}{l}\text { PLT } \\
\text { (K/ul) }\end{array}$ & $\begin{array}{c}\text { GLU } \\
(\mathrm{mg} / \mathrm{dl})\end{array}$ & $\begin{array}{c}\mathrm{AF} \\
(\mathrm{UI} / \mathrm{L})\end{array}$ & $\begin{array}{l}\text { LDH } \\
(\mathrm{U} / \mathrm{L})\end{array}$ & $\begin{array}{l}\text { ALTTGP } \\
(\mathrm{U} / \mathrm{L})\end{array}$ & $\begin{array}{c}\text { ASATTGO } \\
(\mathrm{U} / \mathrm{L})\end{array}$ \\
\hline 13 & M & H. capsulatum & 4.3 & 2.4 & 1.9 & 13.8 & 43.6 & 171 & 83 & 145 & 230 & 46 & 42 \\
\hline 6 & M & H. capsulatum & 7.9 & 6.4 & 1.5 & 13.3 & 40.6 & 403 & 85 & 289 & 218 & 22 & 26 \\
\hline 13 & $\mathrm{~F}$ & C. immitis & 3.7 & 2.1 & 1.6 & 13.8 & 43.9 & 231 & 72 & 153 & 175 & 19 & 24 \\
\hline 12,4 & $\mathrm{~F}$ & C. neoformans & 3.12 & 1.26 & 1.38 & 11.6 & 33.7 & 371 & 102 & 384 & 640 & 28 & 55 \\
\hline 1,10 & M & C. neoformans & 9 & 7.87 & 0.99 & 7.7 & 23.8 & 279 & 239 & - & 1039 & - & - \\
\hline 2,7 & M & H. capsulatum & 5.87 & 3.5 & 1.96 & 6.4 & 21.8 & 277 & 58 & 863 & 1088 & 73 & 129 \\
\hline 11,6 & M & C. neoformans & 4.56 & 3.99 & 0.47 & 9.9 & 30.3 & 278 & 110 & 93 & - & 29 & 54 \\
\hline 0,11 & $\mathrm{~F}$ & H. capsulatum & 17.14 & 4.14 & 10.14 & 9.7 & 32.3 & 194 & 104 & 294 & 1186 & 66 & 142 \\
\hline 14,11 & $\mathrm{~F}$ & H. capsulatum & 0.9 & 0.48 & 0.34 & 4 & 12 & 1 & 94 & 269 & 785 & 13 & 39 \\
\hline 3,11 & M & H. capsulatum & 3.38 & 1.62 & 1.59 & 5.6 & 17.2 & 28 & 62 & 298 & 79 & - & - \\
\hline 10,6 & $\mathrm{~F}$ & C. neoformans & 12.63 & 8.92 & 2.19 & 11.9 & 36 & 578 & 81 & - & 333 & 6 & - \\
\hline 14 & $\mathrm{~F}$ & H. capsulatum & 5.25 & 4.43 & 13.30 & 8.2 & 24.5 & 438 & 187 & 282 & 575 & 6 & 30 \\
\hline 8 & $\mathrm{M}$ & H. capsulatum & 2.65 & 1.97 & 0.68 & 6.2 & - & 10 & - & 248 & - & 42 & 136 \\
\hline 1,2 & M & H. capsulatum & 2.20 & 1.2 & 1 & 7.2 & - & 80 & - & 240 & - & 84 & 125 \\
\hline 0.6 & F & H. capsulatum & 11.29 & 3.16 & 7.1 & 12 & 36.7 & 4 & 81 & 117 & 757 & 85 & 81 \\
\hline
\end{tabular}

WBC: white blood cells. Neut. Neutrophils. Lymph. Lymphocytes. Hb. Hemoglobin. HT Hematocrit. PLT platelets. GLU glucose. AF Alkaline phosphatase. LDH lactic dehydrogenase. ALT Alanine aminotransferase. ASAT aspartate aminotransferase. 
The only case of coccidioidomycosis did not present important changes.

\section{2) Blood chemistry:}

Taking the normal value of alkaline phosphatase up to $270 \mathrm{UI} / \mathrm{L}, 46 \%$ of the children analyzed presented a high value. However, only one of the cases had a value greater than twice the normal value.

Taking $480 \mathrm{UI} / \mathrm{L}$ as the upper limit for lactate dehydrogenase, $58 \%$ of analyzed patients had an altered value. There was a $66 \%$ of altered results in criptococcosis infected patients and $63 \%$ of histoplasmosis infected patients.

Regarding to hepatic profile, $46 \%$ of patients presented an elevation of alanine aminotransferase (ALT) and 75\% presented aspartate aminotransferase (AST) elevation.

From histoplasmosis patients, $66 \%$ of them had elevated ALT or AST values. All cryptococcosis cases presented ALT or AST elevation.

The only case of coccidioidomycosis did not present biochemical alterations.

\section{Discussion}

This study is the first one conducted in a reference hospital in Guatemala describing the characteristics of invasive fungal infections in the pediatric population. The total burden of serious fungal infections in Guatemala is unknown, but it is likely to exceed 268,363 cases (1.7\% of the population), and cases reported in the pediatric population are not common [14].

The incidence reported in the literature of endemic fungal infections in children is lower than in adults, in which HIV infection and reactivation of past infections are predominant risk factors. Due to the rapid progression and poor prognosis of these infections in the pediatric population and the difficulty of microbiological isolation, are generally underestimated [15].

Although age range goes from 11 months to 14 years, there is a trend in children over five years old, especially in the case of HIV infected children (more than $65 \%$ are older than five years). These are children with slow progression of HIV infection that begins with reactivation of past infections, as occurs with adults. However, more than a third of the patients were under five years old, which indicates probable primary infection due to the endemicity of these pathogens in Guatemala.

The distribution by regions was uniform, due to tropical climate in the country and the predominant economic activity, consisting on agriculture and livestock, which favors the cycle of these fungi and high exposure to inocula. However, there is a trend in the central and southeast region, perhaps because of the proximity to the hospital. There were no cases in the northern region. It is possible that the access from these cities to the capital makes it difficult to detect cases. Histoplasma capsulatum had the widest and most uniform distribution in many regions. Regarding frequency, the most isolated fungus was Cryptococcus, however, due to missing files; only 4 cases could be included in the study.

In general, around $80 \%$ of the patients had some disease related to the wea- 
kening of the immune system, as rheumatological disease, chronic kidney disease, and HIV infection (that occurred in 70\%), and a girl with Down Syndrome. HIV infection was the most important risk factor for these infections [16].

There is a possibility of these infections in children without underlying diseases, for example, there were two cases of progressive disseminated Histoplasmosis of the infant, a condition that may go unnoticed and be confused with other diagnoses. Furthermore, there were eight lost cases of Cryptococcosis infection that were not found in the HIV database, despite being a hospital where systematic HIV screening is performed on all patients that present these infections.

Pathogens were isolated from blood, bone marrow, lymph nodes, cerebrospinal fluid, peritoneal liquid, and urine. The yield of the culture of these samples could not be determined because it was not possible to analyze all the samples requested. Although the low profitability of the microbiological isolation for these pathogens is known, Histoplasma predominated in blood, bone marrow and lymph nodes due to its disseminated presentation, and Cryptococcus predominated in fluids, mainly cerebrospinal, due to the fact that more than $90 \%$ of cases with Cryptococcosis produce meningoencephalitis in patients with advanced HIV infection.

The optimal approach requires an early and accurate diagnosis to implement the appropriate antifungal therapy and minimize the use of toxic drugs. Standard methods as culture, histopathology and microscopy often lack sensitivity and specificity. These limitations have promoted the development of non-invasive diagnostics methods for fungal antigens or genetic material detection. Such is the case of galactomannan, 1 - 3 B, D glucan or Histoplasma antigen in urine by enzymatic immunoassay. However, the first two methods are not validated or standardized in children and they are not available in most countries with limited resources. However, Histoplasma antigen has a sensitivity of 95\% in disseminated disease in patients with AIDS and can cross-react with Blastomyces dermatitidis, Paracoccidioides brasiliensis, Penicillium marneffei, Coccidioides immitis and Coccidioides posadasii [17] [18].

The lack of specificity from clinical symptoms causes diagnosis and treatment delayed. Although more than half of the patients did not receive adequate treatment, mortality (which exceeded 50\%) was higher in those who did not receive treatment. It shows a late diagnosis due to the nonspecific presentation of these infections and the difficulty of microbiological isolation. Another problem is the progress of opportunistic and underlying diseases (mainly HIV infection) since these patients are late diagnosed with HIV ( $89 \%$ of HIV patients were in stage three, and one was a stage two infant where the $\mathrm{CD} 4$ value is not predictive).

There should be caution when interpreting the CD4 T lymphocyte value in children $<5$ years infected with HIV, as regards to its relationship with opportunistic infections and the cut-off point, for example for histoplasmosis it is not defined, presenting qualitative alterations rather than quantitative. Furthermore, 
in children, the CD4 count to consider severe immunosuppression is different from that of adults. For example, two of the patients did not have CD4 $<150$ which is the cut-off point for histoplasmosis in adults [19].

Regarding to viral load, older children had values below $100,000 \mathrm{cp} / \mathrm{ml}$, compared to young children, due to the natural evolution of the infection since younger children have higher replication of the virus.

In general, this situation of HIV and fungal infection in children in non-industrialized countries is common; being diagnosed at the same time, with no time for antiretroviral treatment administration.

In most of the cases, signs and symptoms were nonspecific, predominating fever and constitutional systemic signs with involvement of the mononuclear phagocytic system (hepatosplenomegaly, lymphadenopathy).

This supports isolation results, mainly in Histoplasmosis due to its $100 \%$ disseminated presentation. In the case of Cryptococcosis, the classic signs of CNS involvement were isolated from CSF in patients with HIV infection [20].

The lack of specificity from the clinical findings causes the diagnosis and treatment to be delayed. Lab findings show decreased values of hematological parameters in these patients mainly for histoplasmosis and cryptococcosis. This is related to the presence of a secondary Hemophagocytic Syndrome [21].

Anemia and lymphopenia are predominant, being the last one related to the depletion of CD4 $\mathrm{T}$ lymphocytes in patients with advanced HIV infection, caused by the late diagnosis.

The discrete elevations of alkaline phosphatase, lactic dehydrogenase and transaminases were observed in about half of the children. The AST/ALT index of 2.5 or greater, described as a contributor in the diagnosis of disseminated histoplasmosis compared to other IFAs, was observed in three children with this entity, but not in the others. These nonspecific findings should be considered in these infections, mainly in disseminated histoplasmosis [22] [23].

The limitations of this study are that, as it is a retrospective study, some clinical histories were not available to be reviewed with the diagnosis of invasive fungal infection. The lack of some diagnostic techniques that are used today for these infections is also a limitation to our work.

In summary, in countries with tropical climates, such as Guatemala, there should be a higher index of suspicion of regional fungal infections in patients of pediatric age who present a situation of severe hematological cytopenias and neurological symptoms [24].

Although infection by regional fungi can occur in immunocompetent patients, it is necessary to perform screening for immunodeficient patients, including HIV infection, since it is the most important risk factor for IFI in this population. The prognosis of the infection may depend on early diagnosis and treatment.

\section{Acknowledgements}

To the Microbiology Service of the Roosevelt Hospital in Guatemala, for the data obtained from the registration of crops carried out during the observation period. 


\section{Interest Conflict}

The authors did not receive any financial support for carrying out this research or have any conflict of interest.

\section{References}

[1] Theoklis, E. (2010) Invasival Fungal Infections in Pediatric Patients: Challenges to Optimal Management. The Journal of Pediatrics, 156, A1-S86. https://doi.org/10.1016/s0022-3476(10)00060-0

[2] Ramos, J.T., Francisco, L. and Daoud, Z. (2016) Invasive Fungal Infections in Children: Similarities and Differences with Adults. Revista Espanola De Quimioterapia, 29, 59-65.

[3] Alverson, B., Alexander, N., LeGolvan, M.P., Dunlap, W. and Levy, C. (2010) A Human Immunodeficiency Virus-Positive Infant with Probable Congenital Histoplasmosis in a Nonendemic Area. The Pediatric Infectious Disease Journal, 29, 1055-1057.

[4] Sifuentes-Osornio, J., Corzo-Leon, D. and Ponce-de-Leon, L. (2012) Epidemiology of Invasive Fungal Infections in Latin America. Current Fungal Infection Reports, 6, 23-34. https://doi.org/10.1007/s12281-011-0081-7

[5] Adderson, E.E. (2004) Histoplasmosis in a Pediatric Oncology Center. The Journal of Pediatrics, 144, 100-106. https://doi.org/10.1016/j.jpeds.2003.10.035

[6] Assi, M., Martin, S., Wheat, L.J., Hage, C., Freifeld, A., Avery, R., et al. (2013) Histoplasmosis after Solid Organ Transplant. Clinical Infectious Diseases, 57, 1542-1549. https://doi.org/10.1093/cid/cit593

[7] Benedict, K. and Mody, R.K. (2016) Epidemiology of Histoplasmosis Outbreaks, United States, 1938-2013. Emerging Infectious Diseases, 22, 370-378.

https://doi.org/10.3201/eid2203.151117

[8] Joshi, N.S., Fisher, B.T., Prasad, P.A. and Zaoutis, T.E. (2010) Epidemiology of Cryptococcal Infection in Hospitalized Children. The Pediatric Infectious Disease Journal, 29, e91-e95. https://doi.org/10.1097/INF.0b013e3181fbc83d

[9] Nucci, M., Queiroz-Telles, F., Tobón, A.M., Restrepo, A. and Colombo, A.L. (2010) Epidemiology of Opportunistic Fungal Infections in Latin America. Clinical Infectious Diseases, 51, 561-570. https://doi.org/10.1086/655683

[10] Fisher, B.T., Chiller, T.M., Prasad, P.A., Beveridge, M., Walsh, T.J. and Zaoutis, T.E. (2010) Hospitalizations for Coccidioidomycosis at Forty-One Children's Hospitals in the United States. The Pediatric Infectious Disease Journal, 29, 243-247. https://doi.org/10.1097/INF.0b013e3181bcfd7f

[11] Guevara, R., Motala, T. and Terashita, D. (2015) The Changing Epidemiology of Coccidioidomycosis in Los Angeles (LA) County, California, 1973-2011. PLoS One, 10, e0136753. https://doi.org/10.1371/journal.pone.0136753

[12] Revised Surveillance Case Definition for HIV Infection. Morbidity and Mortality Weekly Report. CDC April 11, 2014.

[13] Nathan, D. and Oski, F.A. (1998) Hematology of Infancy and Childhood. WB Saunders, Philadelphia.

[14] Medina, N., Samayoa, B.., Lau-Bonilla, D., Denning, D.W., Herrera, R., Mercad, D., et al. (2017) Burden of Serious Fungal Infections in Guatemala. European Journal of Clinical Microbiology \& Infectious Diseases, 36, 965-969.

https://doi.org/10.1007/s10096-017-2920-0 
[15] Montenegro, B.L. and Arnold, J.C. (2010) North American Dimorphic Fungal Infections in Children. Pediatrics in Review, 31, e40.

[16] Toussi, S.S., Pan, N., Walters, H.M. and Walsh, T.J. (2013) Infections in Children and Adolescents with Juvenile Idiopathic Arthritis and Inflammatory Bowel Disease Treated with Tumor Necrosis Factor- $\alpha$ Inhibitors: Systematic Review of the Literature. Clinical Infectious Diseases, 57, 1318-1330. https://doi.org/10.1093/cid/cit489

[17] Pana, Z.D., Vikelouda, K. and Roilides, E. (2016) Diagnosis of Invasive Fungal Diseases in Pediatric Patients. Expert Review of Anti-Infective Therapy, 14, 1203-1213. https://doi.org/10.1080/14787210.2016.1242413

[18] Azar, M.M. and Hage, C.A. (2017) Laboratory Diagnostics for Histoplasmosis. Journal of Clinical Microbiology, 55, 1612-1620.

[19] Siberry, G.K., Abzug, M.J., Nachman, S., Brady, M.T., Dominguez, K.L., Handelsman, E., Mofenson, L.M., et al. (2013) Guidelines for the Prevention and Treatment of Opportunistic Infections among HIV-Exposed and HIV-Infected Children.

[20] De, D. and Nath, U.K. (2015) Disseminated Histoplasmosis in Immunocompetent Individuals-Not a So Rare Entity, in India. Mediterranean Journal of Hematology and Infectious Diseases, 7, e2015028. https://doi.org/10.4084/mjhid.2015.028

[21] Daher, E.F., Silva, G.B., Barros, F.A., Takeda, C.F., Mota, R.M. and Ferreira, M.T. (2007) Clinical and Laboratory Features of Disseminated Histoplasmosis in HIV Patients from Brazil. Tropical Medicine \& International Health, 12, 1108-1115. https://doi.org/10.1111/j.1365-3156.2007.01894.x

[22] Silva, M.F., Ferriani, M.P., Terreri, M.T., Pereira, R.M., Magalhães, C.S., et al. (2015) A Multicenter Study of Invasive Fungal Infections in Patients with Childhood-Onset Systemic Lupus Erythematosus. The Journal of Rheumatology, 42, 2296-303. https://doi.org/10.3899/jrheum.150142

[23] Spec, A., Barrios, Ch., Ahmad, U. and Proria, L. (2016) AST to ALT Ratio Is Elevated in Disseminated Histoplasmosis as Compared to Localized Pulmonary Disease and Other Endemic Mycoses. Medical Mycology, 55, 541-545.

[24] Giacomazzi, J., Baethgen, L., Carneiro, L., Adelaide, M., Denning, D., Colombo, A., et al. (2016) The Burden of Serious Human Fungal Infections in Brazil. Mycoses, 59, 145-150. https://doi.org/10.1111/myc.12427 